\title{
Erratum to: Internalization and retrograde axonal trafficking of tetanus toxin in motor neurons and trans-synaptic propagation at central synapses exceed those of its $\mathbf{C}$-terminal-binding fragments
}

Saak V. Ovsepian · MacDara Bodeker • Valerie B. O'Leary •

Gary W. Lawrence $\cdot$ J. Oliver Dolly

Published online: 21 March 2015

(c) Springer-Verlag Berlin Heidelberg 2015

Erratum to: Brain Struct Funct

DOI 10.1007/s00429-015-1004-0

Unfortunately, in the original version, the name of the first author has been misspelt as Saak V. Ovespian. The correct spelling for the author's name should be Saak V. Ovsepian.

The online version of the original article can be found under doi:10. 1007/s00429-015-1004-0.

S. V. Ovsepian $(\bowtie) \cdot$ M. Bodeker · V. B. O’Leary ·

G. W. Lawrence · J. Oliver Dolly

International Centre for Neurotherapeutics, Dublin City

University, Dublin 9, Ireland

e-mail: saak.ovsepian@gmail.com

\section{S. V. Ovsepian}

German Centre for Neurodegenerative Disease (DZNE),

Ludwig-Maximilian-Universität München, Zentrum für

Neuropathologie, 81377 Munich, Germany

M. Bodeker

Life Sciences Department, Institute of Technology,

Sligo, Ireland

V. B. O'Leary

Institute of Radiation Biology, Helmholtz Zentrum München,

85764 Neuherberg, Germany 